San Jose State University

SJSU ScholarWorks

Master's Projects

Master's Theses and Graduate Research

$5-17-2000$

\title{
Evaluation of the Effectiveness of the "Youth Leadership" Class in the Prevention of Adolescent Depression
}

Jacqueline Oria

San Jose State University

Follow this and additional works at: https://scholarworks.sjsu.edu/etd_projects

Part of the Pediatric Nursing Commons, and the Public Health and Community Nursing Commons

\section{Recommended Citation}

Oria, Jacqueline, "Evaluation of the Effectiveness of the "Youth Leadership" Class in the Prevention of Adolescent Depression" (2000). Master's Projects. 875.

DOI: https://doi.org/10.31979/etd.hy54-22nw

https://scholarworks.sjsu.edu/etd_projects/875

This Master's Project is brought to you for free and open access by the Master's Theses and Graduate Research at SJSU ScholarWorks. It has been accepted for inclusion in Master's Projects by an authorized administrator of SJSU ScholarWorks. For more information, please contact scholarworks@sjsu.edu. 
SAN JOSE STATE UNIVERSITY

SCHOOL OF NURSING

\section{MASTER'S PROGRAM PROJECT OPTION (PLAN B) \\ PROJECT SIGNATURE FORM}

STUDENT NAME

JACQUELINE ORIA

SEMESTER ENROLLED__ SPRWG 2000

TITLE OF PROJECT

"EUALUATION OF THE EFFEGTIENESS

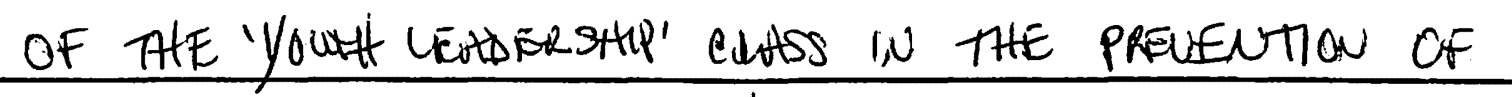
ADOLESCENT DEPRESSION"

NAME OF JOURNAL JOUKRAL OF SGAJOC AMEACTA

The project and manuscript have been successfully completed and meet the standards of the School of Nursing at San Jose State University. The project demonstrates the application of professional knowledge, clinical expertise, and scholarly thinking. An abstract of the project and two copies of the manuscript are attached.
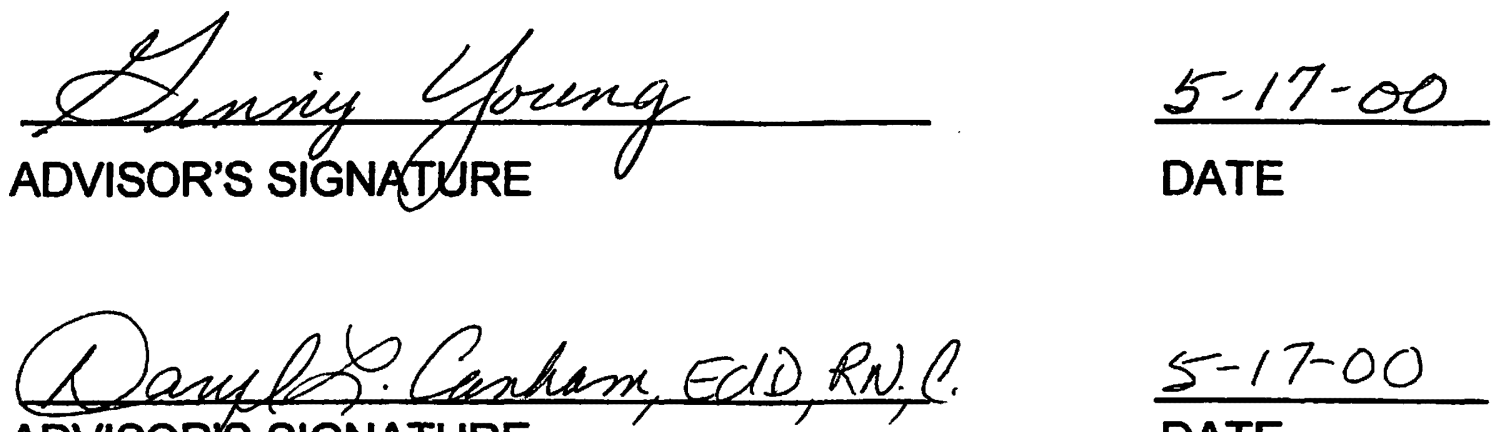

ADVISOR'S SIGNATURE

$\frac{5-17-00}{\text { DATE }}$

Please submit this form to the Graduate Coordinator. Attach abstract, two copies of the manuscript, and documentation of submission to the journal (i.e., postal receipt). 


\title{
EVALUATION OF THE EFFECTIVENESS OF THE "YOUTH LEADERSHIP" CLASS IN THE PREVENTION OF ADOLESCENT DEPRESSION
}

\author{
Authors: \\ Jackie Oria, R.N., MSN \\ Ginny Young-Cureton, Dr. PH, R.N. \\ Daryl Canham, Ed. D., R.N.
}

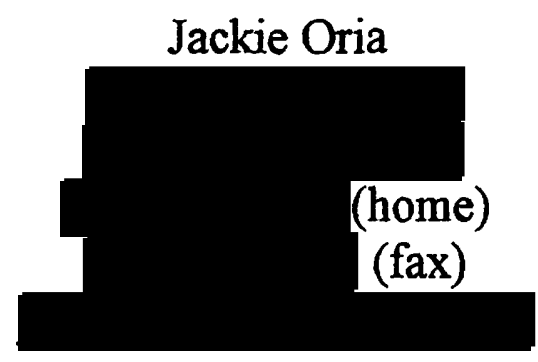

Date ready for submission: July 1, 2000 
Overview

Depression in adolescence is a common and potentially life-threatening health problem. Depending upon the severity of symptoms, anywhere from $2 \%$ to $40 \%$ of teenagers are affected with depression (Sadler, 1993). The purpose of this study is to evaluate the effects of prevention strategies on decreasing the rate of depression in adolescents. It is hoped that a class addressing specific skills identified as having an impact on adolescent depression will affect the youth participating in the program.

The research question is: "What is the relationship between a student's level of depression and participation versus non-participation in the "Youth Leadership" class at a San Francisco Bay Area middle school?". This research was quantitative and quasiexperimental. The nonequivalent control group design was utilized.

The sample consisted of seventh and eighth grade students in either the "Youth Leadership" class or the third period computer class of a Bay Area middle school. The parents/caregivers had to sign and return a letter giving their child permission to participate in the study. The letter described how the study was to be conducted, that approval was obtained by the Human Subjects Review Board at San Jose State University and from the San Francisco Bay Area school district, and that the site administrator had also given approval for the study.

Kovacs' Childhood Depression Inventory (CDI) was the instrument used in the study. It has been used primarily in child ages 7 to 17 years. The CDI consists of 27 items on a three-point Likert scale scored as 0,1 , or 2 based on the response chosen by the child and is easily administered in 10 to 20 minutes. The CDI was administered in early November and again in early March. Only students with signed parental consent were allowed to participate. Nine 
control group subjects and eleven experimental group subjects completed both the pre- and post-tests.

The data analysis compared differences in the pre- and post-test scores for each student (gain score). Mean gain scores were calculated for each group and the median test was used to compare the two groups. Finally, the gain t-test was used to determine statistical significance. The analysis of the data revealed no statistically significant difference between the control and experimental groups. The sample sizes were too small due to parents not wanting their child to participate in the study and students not completing both the pre- and post-tests. Additionally, the pre-test should have been given earlier in the school year. Based on research by Peterson, Leffert, Graham, Alwin, and Ding (1997) this study should be repeated with larger sample sizes and with greater attention to the timing of pre- and post-tests.

Adolescents spend the majority of each day in their respective school setting whether it is middle school, junior high, or high school. School nurses should take an active role in the identification of youths at risk for depression and in those youth who are clinically depressed. Often, school nurses are working at a school in which known risk factors for depression have already been identified in the student population. For example, a particular area may have high rates of poverty, substance abuse, and crime. Also, developmentally or physically disabled students and pregnant adolescents are at increased risk for development of depression. With the understanding that depression in adolescence is prevalent and potentially life threatening, it is imperative that school nurses take an active role in the prevention, recognition, referral, and follow-up care needed by youth. 


\title{
EVALUATION OF THE EFFECTIVENESS OF THE "YOUTH LEADERSHIP" CLASS IN THE PREVENTION OF ADOLESCENT DEPRESSION
}

\author{
A Research Study \\ Presented to \\ The Faculty of the School of Nursing \\ San Jose State University \\ In Partial Fulfillment \\ Of the Requirements for the Degree \\ Master of Science
}

By

Jacqueline Oria

May 17. 2000 


\section{Table of Contents}

Page

$\begin{array}{ll}\text { Research Problem } & 3\end{array}$

$\begin{array}{lr}\text { Research Question } & 6\end{array}$

$\begin{array}{ll}\text { Background Literature Review } & 7\end{array}$

$\begin{array}{ll}\text { Conceptual Framework } & 13\end{array}$

$\begin{array}{ll}\text { Methodology } & 14\end{array}$

$\begin{array}{ll}\text { Research Design } & 14\end{array}$

$\begin{array}{ll}\text { Instrumentation } & 15\end{array}$

$\begin{array}{ll}\text { Subjects and Sampling } & 17\end{array}$

$\begin{array}{ll}\text { Setting } & 17\end{array}$

$\begin{array}{lr}\text { Research Procedures } & 18\end{array}$

$\begin{array}{ll}\text { References } & 21\end{array}$

Appendices

Appendix A: Youth Leadership Class Curriculum $\quad 24$

Appendix B: Mental Health Trajectory $\quad 26$

$\begin{array}{ll}\text { Appendix C: Time Line } & 27\end{array}$

$\begin{array}{lr}\text { Appendix D: Budget } & 28\end{array}$

Appendix E: Letter Requesting Permission for use of Agency 29

Appendix F: Human Subjects Application 30

Appendix G: Consent Form 33

Appendix H: School District Parent Permission Letter 35

Appendix I: Table 1 and 2 
Evaluation of the Effectiveness of the "Youth Leadership" Class in the Prevention of Adolescent Depression

Depression in adolescence is a common and potentially life-threatening health problem. The cause is not adolescence itself, but the normal losses and stresses that occur during the developmental process. Some individuals may be unable to effectively cope with the various stressors. Depending upon the severity of the symptoms, anywhere from $2 \%$ to $40 \%$ of teenagers are affected with depression (Sadler. 1993).

Depression is defined by Brage (1995) as "...dysphoric mood or loss of interest or pleasure in the person`s usual activities characterized by persistent symptoms such as hopelessness. irritability, or feeling blue or sad" (p. 45). In addition to the developmental stage of adolescence, many factors play a role in the emergence of a depressive episode. For example. class. race. peer group, and family relations affect an adolescent and may precipitate depression. Family history of mental illness, abuse (physical, emotional, or sexual), chronic illness, and the loss of a parent through death. divorce. or abandonment are also risk factors for depression (Gray. 1999). Poverty and minority ethnic status are linked to higher rates of depressive illness. Youth who are questioning their sexual identity have extremely high rates of depression and suicide. Additionally. females report feelings of depressed mood more often than do males (Sadler. 1993). Rice and Leffert (1997) report that eating disorders and substance abuse are co-morbid with depression and that suicide rates among adolescents and young adults with a mood disorder is 25 times greater than the general population (p. 20). The Centers for Disease Control (1997) ranked suicide as the third leading cause of death in 10 to 24 year olds.

The characteristics of depression are numerous and include: sad mood, decreased interest in daily activities, significant weight loss or gain. sleep disturbances, lethargy, fatigue, guilty or worthless feelings. lack of concentration, and repetitive thoughts about death and/or suicide 
(Sadler, 1993). Adolescents may also exhibit certain behaviors such as: academic deterioration, substance abuse. sexual activity, somatic complaints, eating disorders, conduct disorders, and other risk-taking behaviors. In adolescents the symptoms range from mild to severe: $13.5 \%$ exhibit mild depression, $7 \%$ moderate, and $1.3 \%$ to $5 \%$ experience severe depression. The rate of depression seems to be rising in the 15-19 year old age group (Sadler, 1993). Shaffer et al. (1996) conducted an epidemiological study sponsored by The National Institute of Mental Health on depression in 9 to 17 year olds. Shaffer et al. research revealed that more than $6 \%$ of the children were experiencing depression and $4.9 \%$ of them had major depression.

As youth struggle with the many changes that are occurring during the transition into adolescence. a series of losses occur that can impact the adolescent's emotional stability. Separation from parents is a normal developmental task. but one that can result in feelings of guilt, ambivalence. and helplessness. This time period also represents a loss of freedom from responsibility and a loss of sexual innocence. Finally, youth may experience loss of self-esteem. Adolescents who are chronically ill. obese. or perceive themselves as different often have a low self-concept which can result in lowered self-esteem and depression (Sadler. 1993).

Adolescents with depressive disorders may have a recurrence rate as high as $64 \%$ according to McFarlane, Bellissimo, Norman. and Lange (1994). These researchers also noted an increased risk for disorder and dysfunction in young adulthood. However, of great importance was evidence that depression in adolescence was the most significant indicator of adult depression. Additionally, it has been proven that females have higher divorce rates and estrangement from parents whereas males have higher rates of unemployment and car accidents. Both sexes are at increased risk for decreased intimacy with their significant other and for illegal activities (McFarlane et al.. 1994). 
Depression in adolescence can be classified into six major categories. First is the major depressive episode. which is characterized by the symptoms listed previously. This condition may last months if untreated and frequently is associated with a family history of depression and alcoholism (Sadler. 1993). Research conducted by Weissman et al. (1999) revealed that adolescents diagnosed with major depressive disorder are at greater risk of committing suicide in the young adults years. as many as $7 \%$. Next. bipolar depression disorder is characterized by manic episodes (irritable or grandiose behavior) and is linked to a positive family history as well. Organic depressive disorder occurs after exposure to toxins. head injury. or from endogenous conditions. A more mild form of depression. dysthỵmia. has in insidious onset and is usually a chronic condition. Following a divorce. natural disaster. phỵsical injury. or household move. an adolescent may suffer from adjustment disorder. Finally, the death of a family member or a significant physical loss may result in depression. Bereavement may last for a year or more. with anniversaries of events renewing depressed feelings (Sadler. 1993).

Each year a San Francisco Bay Area urban school district conducts a survey entitled "The Youth Risk Behavior Survey" (Centers for Disease Control. 1997). Following is a sampling of the results from the 1997 survey. Sixty-one percent of middle school students said that they felt "sad and depressed" from 1 to 9 days during the previous month. Female students $(83 \%)$ were more likely than male students ( $71 \%$ ) to have felt sad and depressed. Over $24 \%$ of middle school students said they had seriously thought about ending their lives and $10 \%$ of middle school students reported having attempted suicide at least once. Fifiv-three percent of middle school students reported having tried alcohol at least once and $37 \%$ have tried smoking at least once. Forty-five percent of sexually active middle school students have had at least three partners 
(CDC, 1997). The U.S. Census Bureau (1995) reports $20 \%$ of San Francisco's children ages 5 to 17 years live in poverty.

Adolescents spend the majority of each day in their respective school settings whether it is middle school. junior high, or high school. It seems logical that school nurses would take an active role in the identification of youths at risk for depression and in those youth who are clinically depressed. Often. nurses are working at a school in which known risk factors for depression have already been identified. For example. a particular area may have high rates of poverty, substance abuse. and crime. Also. developmentally or physically disabled students and pregnant adolescents both are at increased risk for development of depression.

The purpose of this study is to evaluate the effects of prevention strategies on decreasing the rate of depression in adolescents. It is hoped that a class addressing specific skills identified as having an impact on adolescent depression will affect the youths participating in the program. The target population will be adolescents in middle school. ages 11-14 years in grades 6-8. For the purpose of this study, this age group of adolescents will be referred to as "early adolescents".

\section{Research Question}

What is the relationship between a student's level of depression and participation versus nonparticipation in the "Youth Leadership" class at a San Francisco Bay Area middle school?

\section{Hvpothesis}

The level of depression in the early adolescents who attend the "Youth Leadership" class will be lower than the level of depression of those early adolescents who do not attend the class.

For the purposes of this study, students attending the seventh and eighth grades at a San Francisco Bay Area middle school were the subjects. Depression is defined (as previously mentioned) by Brage (1995) as "...dysphoric mood or loss of interest or pleasure in the person's 
usual activities characterized by persistent symptoms such as hopelessness, irritability, or feeling blue or sad" (p. 45). The "Youth Leadership" class meets every day during one 50-minute period for the entire school year. The primary purpose of the class is to teach the students "life skills." The students have an opportunity to utilize the newly acquired skills as they set-up and conduct a youth court. The specific "life skills" that are taught include: values. communication styles, question asking, listening, forced choices, decision making. consequences, peer pressure, anger management. facilitation skills. leadership techniques. goal setting, note taking, conflict management. and slammers (a game which teaches a person attentive listening skills).

\section{Literature Review}

Prior to 1980 , some professionals believed that depression was an illness from which only adults suffered. The rationale for this belief was that childhood depression could not exist because it was a superego phenomenon and that children did not have a superego developed to the extent that allowed for development of depression. With the advent of empirically based instruments to study this disorder. the diagnosis of childhood depression became an accepted notion (Matson. 1989): There was still much controversy however about if and how depression in children differed from adult depression. The previously mentioned instruments allowed researchers to compare adult and adolescent forms of depression and conclude that symptoms are similar with only a few exceptions. Mellencamp (1981) noted that adolescents tend to feel depressed constantly throughout the day whereas adults usually feel worse in the morning and better in the evening. The author also points out that although the severity of symptoms may be equivalent between childhood and adult depression, adolescents are often more destructive and have greater suicidal actions. Also of importance is that social abandonment and acting out 
behaviors are two characteristics found particularly in the adolescent population (Mellencamp, 1981).

Much of the research conducted thus far on adolescent depression has focused on diagnosis. treatment, and identification of causative factors of the condition. Controversy over the cause of this condition has existed since its official recognition. More recent literature is beginning to focus on the numerous possible etiologies of adolescent depression and specifically effective preventative measures.

Numerous instruments exist to aid professionals in the diagnosis of depression in adolescents. These self-report questionnaires and rating scales are best judged in conjunction with clinical interviews or behavioral observation. Sadler (1993) lists the most widely used and accepted instruments as: the Beck Depression Inventory, the Children 's Depression Inventory, the Center for Epidemiologic Studies Depression Scale. the Children`s Depression Rating Scale. and the Reynolds Adolescent Rating Scale. There is also a specific set of criteria as outlined in The Diagnostic and Statistical Manual of Mental Disorders that must be present in order for a diagnosis of major depression to be made. The manual provides a list of symptoms. minimum number of symptoms to be present. and the minimum time symptoms are to be present (American Psychiatric Association. 1994).

Treatment measures for adolescent depression include: cognitive-behavioral therapy, family therapy, and drug therapy (Brage. 1995). The goals of cognitive-behavioral therapy are to improve the adolescent's interpersonal skills and alter his/her negative self-perceptions. whereas family therapy seeks to help the parents develop better parenting and nurturing skills. Although most adolescents are not treated with drug therapy, those adolescents that receive medication 
generally are seriously depressed and respond to antidepressants similarly to adults (Brage. 1995).

Matson (1989) has grouped the theories supporting the etiologies of adolescent depression into two main areas: biological and psychological. Biochemistry is a possible cause of this adolescent condition: however. much of the data supporting this theory is based on extrapolations from adult literature. The most compelling argument for a biological basis of depression in childhood is the developmental course. Research has shown an increase in the rate and severity of depression as the youth progresses through adolescence. Also of note is the fact that an adolescent is more at risk for developing depression if a family historg. of depression exists. This explanation tends to be more demonstrative when depression is extreme (.Matson).

The first psychological explanation of adolescent depression is the theory of sell-regulation. The most important assumption of this theory is "...that environmental stimulation and momentary environmental events are regulated by biological variables that produce behavior* (Matson. 1989. p. 17). Treatment focuses on teaching the youth to control hisiher environment by changing personal choices and changing his/her perception of the environment.

The next theory in the psychological arena is learned helpiessness. According to the theory. four deficits exist within the individual: motivational. cognitive. affective-somatic. and selfesteem. There are also several premises included in the theory. This theory. however. is not as popular as it was in the 1970's and has never had a strong link between theory and trearment (Matson. 1989).

Social learning theory refers to a person's ability to gain reinforcement from his/her environment in the form of sympathy and attention for his/her depressive verbal and nonverbal behaviors. Lewinsohn. Gotlib, and Seeley (1997) believe that decreased positive reinforcement 
leads to more depression. lower self-esteem. and increased feelings of inferiority. Thus. positive. non-depressive behaviors need to be reinforced.

Finally, research has shown that parental behaviors may be associated with childhood depression. Depressed parents have poor parenting skills, greater difficulty showing affection, and communicate poorly with their children (Matson. 1989). Also. it was demonstrated that depressed children received fewer rewards from their parents when compared to non-depressed children (Matson).

Numerous studies have documented the role of family and or peer influences on adolescent depression. For example. Garber. Robinson. and Valentiner (1997) found that low levels of maternal acceptance and high levels of maternal psychological control were linked to depressive symptoms in children. Also. the researchers revealed a relationship between self-esteem. self-worth. and depression. Children learn to value themselves in part by how others view them. Low self-worth leads to low self-esteem. which in turn can lead to depressive symptoms.

Sheeber. Hops. Alpert. Davis. and Andrews (1997) found similar results when they studied the effects of family support and family conflict on adolescent depression. Data revealed greater depressive s!mptoms in adolescents whose families were less supportive and experienced a greater number of conflicts. These results suggest a causal influence of family relationships on depression. There was no difference found between male and female adolescents.

In a study performed by Lewinsohn. Gotlib. and Seeley (1997) three variables were found to be specific to depression: self-consciousness. self-esteem. and a change or decrease in activities due to physical illness. The researchers also concluded that a measure of self-esteem might assist with predicting the onset of depression. Additionally, contrary to previous studies. low social support from family members was found to be nonspecific to depression. 
McFarlane. Bellissimo, and Norman (1995) looked at the role of family and peers in social self-efficacy and the link with adolescent depression. The results revealed that social self-efficacy and social support acted as protective factors against depression. Although peer support did not have a direct significant effect on depression. it did have a positive relationship with social self-efficacy. Peer support furthers the development of social skills thus strengthening social self-efficacy. Moreover. the researchers discovered that if the adolescent's family is unavailable, the youth may not always turn to peers since peer relationships can be a source of stress. In this study, females demonstrated increased vulnerability to depression. The researchers concluded by recommending intervention strategies aimed at developing social self-efficacy and decreasing stressors for youth.

An article by Rice and Leffert (1997) discussed assessment. referral. and counseling services for the depressed adolescent. and also prevention strategies based on factors identified by many researchers as increasing an adolescent's risk for development of depression. Of interest is this statement made by Rice and Leffert. “...the number of adolescents who could benefit from counselling or other intervention exceeds the capacities of most community professionals and paraprofessionals" (p. 25). This statement underscures the need for prevention efforts. The model suggested by Rice and Leffert focuses on enhancing internal resources (e.g.. coping style) and external resources (e.g., social support). as well as ensuring the availability and utility of these resources when needed. Interventions should be directed toward normative challenges such as: puberty and school transitions and the non-normative such as: divorce and death. The intervention program the researchers evaluated involved teaching emotional. cognitive. and behavioral responses to the stressors and challenges faced by adolescents. Finally, the authors 
recommend that schools teach curriculum that includes depression-related content where appropriate.

Petersen. Leffert. Graham. Alwin. and Ding (1997) completed a study at Penn State aimed at primary prevention of depression in adolescents. Their population consisted of sixth graders from two local schools. The intervention program was designed to teach youth adaptive emotional. cognitive. and behavioral responses to stressors and to decrease the development of symptoms of depression. Emphasis was placed on the adolescent`s ability to learn to cope with everyday stressors such as daily hassles. developmental transitions. stressful life events. and chronic strains. The main goal of the program was development of intrapersonal and interpersonal coping mechanisms. This study used Kovacs`Children`s Depression Inventory (CDI) as one measure of depressive symptoms. The results revealed better coping by the adolescents for the short term. Also. adolescents identified at high risk for depression benefited more from the intervention than did those adolescents at low risk. However. the intervention did not persist in influencing an adolescent $\mathrm{s}$ ability to cope or in decreasing the rate of depression approximately one year later. Petersen et al. conclude that coping skills can be taught and that these skills decrease the likelihood of depressive symptoms. particularly in girls. Since the effects of the intervention did not persist. the researchers recommend "booster sessions" periodically. The researchers believe this program should be implemented in schools, stating "even short-term benefits could give adolescents another year or two on a more positive trajectory, improving the likelihood of longer-term effects for at least some youths" (p. +92).

The "Youth Leadership" class that is taught at the study middle school includes most of the skills that the Petersen et al. (1997) intervention reviews. The goal of Petersen et al. was to teach youth adaptive skills to deal with stressors in emotional. cognitive, and behavioral areas in 
sixteen 40-minute sessions. The topics covered in the Penn State study are: wheel of life. problem-solving method. generating alternative solutions. assertiveness. emotion-focused coping, relaxation training. anticipating consequences. self-esteem. shyness. friendship. peer pressure, and problem solving in the family (Petersen et al., 1997. p. 483). The "Youth Leadership" class is taught every day for 50 minutes. It covers four main areas: communication skills, anger management. school success. and stress management (see Appendix A for a complete listing). Of the sixteen sessions in the Penn State research study. almost all are covered within the "Youth Leadership" class (Petersen et al.). Petersen et al. rccommend that a primary intervention strategy be implemented in every school: the "Youth Lcadership" class members should be surveyed to see if the class is effective in preventing depression.

\section{Conceptual Framework}

The theoretical framework that guides the research questions is the model of developmental transitions by Petersen and Ebata (1987). This model (see Appendix B) depicts the development of mental health from childhood into adolescence. describing how the number and timing of changes affect mental health. Childhood experiences and expectations of adulthood influence the adolescent. as well as family. peer group. and school. There are acknowledged normative expectations for developmental changes and social tasks. Should these events occur too early or too late, the adolescent may feel as if he/she has violated a social norm (Petersen \& Ebata). Petersen and Ebata also suggest that individuals differ in their responses to normative and nonnormative life events (e.g., death. divorce) due to age as well as unique individual characteristics. Coping skills of the adolescent and parental/peer support are moderators of these effects. An individual's ability to cope depends on that person's strengths and vulnerabilities in the areas of intelligence. self-esteem. and social skills (Petersen \& Ebata, 1987). Peer group is 
seen as an important social support for the adolescent. Studies have shown that "well adjusted" adolescents maintain close relationships with their families throughout adolescence (Petersen \& Ebata). The challenges of adolescence can be growth-inhibiting and/or growth-enhancing, with adequate support and coping skills this time in life can be positive and fulfilling. The "Youth Leadership" class teaches coping skills to young adolescents so that they might be better able to deal with the challenges of this period.

\section{Methodology}

Research design. As stated previously, seventh and eighth grade students at a San Francisco Bay Area middle school were the subjects of this study. Approximately 15 students. 8 seventh graders and 7 eighth graders participated in the "Youth Leadership" class. Students that were not in the seventh or eighth grade honors class or the seventh grade reading class third period were chosen randomly by the computer to participate in either the "Youth Leadership" class or a computer class third period. The researcher did not have any influence on subject selection. The reading class was for those students who are not reading at a seventh grade level. The students that were in the "Youth Leadership" class or the computer class are average students. i.e. not performing above or below the norm. This research project was quantitative and quasiexperimental. The nonequivalent control group design was chosen for this research project. During the beginning of the school year. the Kovacs' Childhood Depression Inventory (CDI) was administered to the students who attended the "Youth Leadership" (approximately 15 students) and computer class (approximately 15 students). During the spring semester. Kovac's CDI was administered to all the "Youth Leadership" and computer class students again. Results were analyzed by comparing subjects who participated in the "Youth Leadership" class versus 
subjects who participated in the computer class. Each group had approximately 15 students for a total number in this study of approximately 30 students.

Instrumentation. The CDI is considered to be the most thoroughly researched self-report measure of childhood and adolescent depression (Matson, 1989). Davis, Hunter, Nathan, and Baimsfather (1987) describe the CDI as a tool that quantifies a wide range of depressive symptoms including disturbances in mood. sleep and appetite. interpersonal behavior, and suicide ideation. Also, several items specifically address being depressed at school. The CDI overlaps considerably with the Diagnostic and Statistical Manual of Mental Disorders (DSM-III) and the Feighner-derived Weinberg criteria that are the acknowledged standards for assessment of depression in children (Davis. et al.. 1987). Reliability and validity have been documented by many studies (Donnelly \& Wilson. 1994; Garber. Robinson. \& Valentiner. 1997: Helsel \& Matson. 1984). The CDI is based on the adult measure, the Beck Depression Inventory. and has been used primarily with children ages 7 to 17 years. Kovacs' CDI consists of 27 items on a three-point Likert scale scored as 0.1 , or 2 based on the response chosen by the child and can easily be administered in 10 to 20 minutes. A sample item is as follows: "I am sad once in a while" (0). "I am sad many times" (1), and "I am sad all the time" (2). Donnelly and Wilson (1994) believe that this "...format provides a degree of control over the effect of acquiescence responding" (p. 426). Respondents are asked to analyze their feelings over the past two weeks when answering the items. Only a first-grade reading level is necessary to complete the instrument. Scores range from 0 to 54 , with higher scores indicating depression. For optimal sensitivity, it is recommended that a lower cutoff of 11 be used. However, for increased specificity, 13 is the recommended cutoff (Davis, et al., 1987): thus. a score of 13 or above indicates depression (Vella, et al., 1992). A short form of 12 items is also available. 
Many researchers have utilized the CDI in their studies and have validated the efficacy of the tool. Donnelly and Wilson (1994) report the internal consistency of the CDI measured by Cronbach's coefficient as 0.8 and item-total correlation's as ranging from 0.2 to 0.5 (p. 426). The CDI has been found to be a stable indicator of depression over time and correlates highly with clinician ratings of depression (Matson. 1989). Additionally, high internal consistency has been established. In a study by Garber, Robinson, and Valentiner (1997) internal consistency was documented as 0.87 for their sample (p. 19). Also, the CDI has been factor analyzed to reveal the following four subdomains: affective behavior. image/ideation. interpersonal relations. and guilt/irritability (Helsel \& Matson. 1984). This information further supports the view that depression in young people is multidimensional. Of interest is the fact that Kovacs found only one factor for depression and feels that the CDI is a unidimensional scale (Donnelly \& Wilson. 1994).

Helsel and Matson (1984) factor analyzed the CDI in order to determine if particular subtopics or symptom clusters existed. Their research revealed the four factors mentioned previously (affective behavior, image/ideation, interpersonal relations. and guilt/irritability). Also. the factors proved to have good face validity as evidenced by consistent content across items. The researchers also assessed the internal validity of the instrument using the average split-half correlation resulting in a highly significant coefficient of 0.89 (p. 291). The SpearmanBrown and the Guttman split-half correlation's were computed resulting in $R=0.85$ and $R=0.84$ respectively (p. 291). Helsel and Matson concluded that both measures of internal consistency were high when compared to other tools used in the evaluation of childhood depression. 
Subjects. sampling. and setting. The population of students at the study middle school consists of many different ethnic groups including African-American. Samoan. Chinese. Japanese, Vietnamese. Hispanic. Filipino. and Caucasian. The majority of the students is of a lower socio-economic status and receives either reduced fee or free breakfast and lunch. Most students live in an urban area that has a high crime rate. primarily involving drugs and violence. Few students live with both parents. many live in single family homes with a parent. grandparent. or foster parent. and a few reside in group homes. Research has linked higher rates of depressive illness with poverty and minority ethnic status. Also. class. race. peer group. and family relations affect an adolescent and may precipitate depression (Brage. 1995).

Approximately 500 students attend the study middle school and are equally distributed between sixth, seventh. and eighth grades. The student body includes youth in general education and special education. The special education program includes resource services and special day classes for the learning handicapped. There are no students classified as severely emotionally disturbed at Visitacion Valley Middle School.

Seventh and eighth grade students were the subjects in this study. These students were in the general education and resource specialist programs only. Demographic data such as gender. ethnicity, and GPA was available from the Hemlock system at the school site. A letter was mailed home to the parent/caregiver of the seventh and eighth grade students asking that they participate in the study. These students were in the "Youth Leadership" and third period computer class. The parent/caregiver had to sign and return the letter in order for his/her child to participate in the study. The letter described how the study was to be conducted. that approval was obtained by the Human Subjects Review Board at San Jose State University and from the San Francisco Bay Area school district, and that the site administrator had also given approval 
for the study. Additionally, the letter included information regarding confidentiality of data obtained (see Appendix H).

\section{Research Procedures}

Kovacs' CDI was given as a pre-test in the "Youth Leadership" class and third period computer class at the beginning of November. The CDI was given in a group setting by the researcher. The school's Peer Resource Coordinator. who is trained in the curriculum utilized in the "Youth Leadership" class. is teaching the "Youth Leadership" course. The Peer Resource Coordinator is a full-time employee of the school site and works one-on-one with students when not teaching. The sessions were 50 minutes long each day. In March. all seventh and eighth graders participating in the two classes completed the CDI as a posttest during third period. in a group, supervised by the researcher.

Each student's name was coded to a number on the CDI both times it was completed. The researcher kept the student's names and scores confidential by locking the coding sheet and score sheets in a file cabinet in the school nurse 's office. Only the researcher has a key to the cabinet. It is necessary to have the student's names in order to identify those students who have completed the course and those students who have not. Results were not compared on an individual basis, but as a group score. The researcher notified the parent/caregiver of any student receiving a score on the $\mathrm{CDI}$, which is possibly indicative of depression, and recommended consultation with the school psychologist or other mental health care provider. In this study, the data analysis examined differences in the pre and post-test scores. The difference between these scores was identified as a "gain" score. The scores for each subject were obtained by subtracting the pretest score from the posttest score. Mean gain scores were calculated for each of the two groups and the median test was used to compare the two groups to see if the students from the 
"Youth Leadership" class scored lower than those students in the computer class. Additionally, demographic data for each group of students were analyzed to ensure that the groups being compared were similar. A statistician was consulted prior to implementation of the study and the statistician analyzed the data.

An anticipated limitation of the study is that a causal relationship between the "Youth Leadership" curriculum and prevention of adolescent depression cannot be made. A limitation of the quasi-experimental design. is that it is only possible to describe changes that occurred after an intervention. Due to inadequate control and the potential for bias. causal explanations cannot be considered. Another limitation of the study is the generalizability of the results. A different person at each of the middle schools teaches the "Youth Leadership" class: some instructors may not be as effective as other instructors. Although students were randomly assigned to either the "Youth Leadership" class or to the computer class. a third limitation is only students who wanted to participate and whose parents signed the permit did participate. Therefore the sample is a convenience sample.

\section{$\underline{\text { Results }}$}

The analysis of the data revealed no statistically significant difference between the control (the students in the computer class) and the experimental group (the students in the "Youth Leadership" class). The mean score on the CDI for the total sample in the control group was $-.667(\mathrm{SD}=2.915)$. The mean score for the total sample in the experimental group was $-3.455(\mathrm{SD}=5.317)$. Results are available in Table 1. Appendix I. The degrees of freedom were 18. The t-test for equality of means was 1.405 with a two-tailed significance of .177 (see Table 2 , Appendix I). Results are not significant based on $\mathrm{p}<.05$. 
Only 9 subjects in the control group and 11 subjects in the experimental group completed both the pre- and posttests. Three subjects in the control group and one in the experimental group were not able to participate due to parental request for non-participation. Also, another student in the experimental group was unable to participate because the student joined the class after the pretest had been administered.

\section{$\underline{\text { Discussion }}$}

The results of this study do not support the hypothesis stated previously. Several factors have been identified as possibly affecting the results. First, the sample sizes were too small. Second. the pretest was not given at the beginning of the school year (September): it was given in early November due to circumstances beyond the researcher's control. Based on the promising results from Peterson. et al. (1997) this study should be repeated with larger sample sizes and with greater attention to timing of the pre/post tests.

\section{Conclusion}

With the understanding that depression in adolescence is prevalent and potentially life-threatening, it is imperative that school nurses begin to take an active role in the prevention. recognition. referral. and follow-up care needed by youths. School nurses can be instrumental in ensuring that mental health needs of students are addressed. Today`s youth are tomorrow`s adults and leaders: ensuring that they are mentally healthy is a task worthy of the challenge. 


\section{References}

American Psychiatric Association. (1994). Diagnostic and statistical manual of mental

disorders $\left(4^{\text {th }}\right.$ ed.). Washington. DC: American Psychiatric Association.

Brage, D. G. (1995). Adolescent depression: A review of the literature. Archives of Psychiatric Nursing. 9 (1). 45-55.

Centers for Disease Control. (1997). Ten leading causes of death. united states [On-line]. Available: www.cdc.gov/ncipc/ospistates/101c97.htm.

Centers for Disease Control (1997). San Francisco Unified School District Youth Risk Behavior Survev.

Davis. T. C.. Hunter. R. J.. Nathan. M. M.. \& Bairnsfather. L. E. (1987). Childhood depression: An overlooked problem in family practice. The Journal of Family Practice. 25 (5). $451-457$.

Donnelly, M.. \& Wilson. R. (1994). The dimensions of depression in early adolescence. Personalitv and Individual Differences. 17 (3). $+25-430$.

Garber. J.. Robinson. N. S., \& Valentiner. D. (1997). The relation between parenting and adolescent depression: Self-worth as a mediator. Journal of Adolescent Research. 12 (1). 12-33.

Gray, D. E. (1999). Children and depression. Wing of Madness: A Depression Guide [on-line]. Available: www.wingofmadness.com/children.htm.

Helsel, W. J.. \& Matson. J. L. (1984). The assessment of depression in children: The internal structure of the child depression inventory (CDI). Behaviour Research and Therapv. 22 (3). 289-298.

Lamarine, R. J. (1995). Child and adolescent depression. Journal of School Health. 65. 390393. 
Lewinsohn, P. M., Gotlib. I. H., \& Seeley. J. R. (1997). Depression-related psychosocial variables: Are they specific to depression in adolescents? Journal of Abnormal Psvchology. 106 (3), $365-375$.

Matson, J. L. (1989). Treating depression in children and adolescents. New York: Pergamon Press.

McFarlane, A. H.. Bellissimo. A.. \& Norman. G. R. (1995). The role of family and peers in social self-efficacy: Links to depression in adolescence. American Journal of Orthopsvchiarty. $\underline{65}(3) .402-410$.

McFarlane, A. H.. Bellissimo. A.. Norman. G. R.. \& Lange. P. (1994). Adolescent depression in a school-based community sample: Preliminary findings on contributing social factors. Journal of Youth and Adolescence. 23. 601-620.

Mellencamp. A. (1981). Adolescent depression: A review of the literature. with implications for nursing care. Journal of Psvchosocial Nursing and Mental Health Services, 19. 15-20.

Petersen. A. C.. \& Ebata. A. T. (1987). Developmental transitions and adolescent problem behavior: Implications for prevention and intervention. In K. Hurrelmann. F. X. Kaufmann. \& F. Losel (Eds.). Social intervention: Potential and constraints (pp. 167-184). New York: Walter de Gruỵter.

Petersen, A. C.. Leffert. N.. Graham. B.. Alwin. J.. \& Ding, S. (1997). Promoting mental health during the transition into adolescence. In J. Schulenberg, J. L. Maggs, \& K. Hurreimann (Eds.), Health risks and developmental transitions during adolescence (pp. 471-497). New York: Cambridge University Press.

Rice, K. G., \& Leffert. N. (1997). Depression in adolescence: Implications for school counsellors. Canadian Journal of Counselling. 31 (1), 18-34. 
Sadler, L. S. (1993). A review for school nursing professionals: Adolescent depression. Journal of School Nursing. 9 (1), 12-19.

Shaffer, D. Fisher, P., Dulcan, M.. Davies, M.. Piacentini, J., Lahey, B., Bourdon, K.. \& Jensen, P. (1996). The second version of the NIMH diagnostic interview schedule for children (DISC-2). Journal of the American Academy of Child and Adolescent Psychiatrv. 35 (7), 865-877.

Sheeber. L.. Hops, H.. Alpert. A.. Davis, B.. \& Andrews. J. (1997). Family support and conflict: Prospective relations to adolescent depression. Journal of Abnormal Child Psvchology, $\underline{25}(4), 333-344$.

U. S. Census Bureau. (1995). County estimates for related children age 5 to 17. Families in Povertv for California.

Vella, D. D.. Heath. N. L., \& Miezitis. S. (1992). Depression in children and adolescents: Assessment issues. In S. Miezitis (Ed.). Creating alternatives to depression in our schools: Assessment. intervention. prevention (pp. 95-106). Seattle: Hogrefe \& Huber Publishers.

Weissman. M. M., Wolk, S., Goldstein. R. B., Moreau. D.. Adams. P.. Greenwald. S.. Klier. C. M., Ryan. N. D.. Dahl, R. E.. \& Wickramaratne. P. (1999). Depressed adolescents grown up. Journal of the American Medical Association. 281, 1701-1713. 


\author{
Appendix A \\ Youth Leadership Class Curriculum \\ Fall 1999 \\ Erin Bristow . \\ VVMS
}

The curriculum for the first 6-week grade period will consist of teaching from the basic skill curriculum from Peer Resources. These consist of the following:

Values Communication stylesQuestion asking

Listening Slammers Forced choices Decision making

Consequences Peer pressures Anger management

Facilitation skills Leadership techniquesGoal setting

Note taking Conflict management

The class will be broken up into small groups for many of the lessons and brought back together to share what they learned. The group will have team building days, where games and strategies are utilized to encourage group dynamics and shared responsibility on decisions.

The class will also begin to develop sentences for the court and work with outside professionals in the legal field. to understand more about youth justice systems and how courts and juries work.

Proposed speakers include:

Attorneys

Law students

Police officers/school patrol car

Probation officers

Street law speakers

Jury pool participants

Judge/commissioner

Referrals from the bar association

During the second 6-weeks, we will begin mock trials to allow the youth to practice with the group, cleaning up problems that will undoubtedly develop throughout the sessions. I would like to begin holding court sessions in October.

Trainings will continue and topics will be introduced to the group as they grow and build their own dynamics. Depending on the issues we see in court. lessons will be made to educate the youth and give insight on the legal ramifications of the cases. 


\section{Court Set-Up}

Two teams of judges/commissioners. The group will role play within their groups. with different situations for the youth court juries. After all the students have been through the mock court sessions as both a defendant. a juror. and a commissioner. then the first team of actual judge/jury will be assembled and court will be ready to go.

We will take referrals from Pupil Services and give the defendants a chance to try the youth court system. There needs to be an alternative to their sentence. such as suspension or a parent conference. We need to have some undesirable alternative. in order for this process to work. It will not be embraced unless it proves to be an alternative to bigger punishment.

The team teaching advantage will be extremely useful when youth court is in session. The jury panel can hold court and the other jury panel can continue to work on other class assignments. This discussion will allow everyone to stay on task and be productive. Each jury will hear cases one day and deliberate on the sentencing the next. Then the jury will reconvene and give the decision to the defendants.

The juries will switch each session and the other group will hear the cases. This method will allow everyone to have a turn at sitting on a jury and will allow the youth to practice their skills.

Other topics to be discussed fall/spring semesters:

Labor law and youth

Street law

Tolerance

Racism

Anger and violence

Gang prevention

The media and pressure on vouth

Advertising

Youth advocacy

Services available to youth

High school opportunities/college

Test taking strategies

Outside Agency Collaboration

Community agencies will be utilized to educate the youth on various issues:

Crisis intervention Mental health/teen clinics

Suicide prevention $\quad$ Tolerance $\quad$ Gang prevention

Drug use GraffitiSummer jobs/careers

Laws and sentencing of the juvenile justice system 
Appendix B

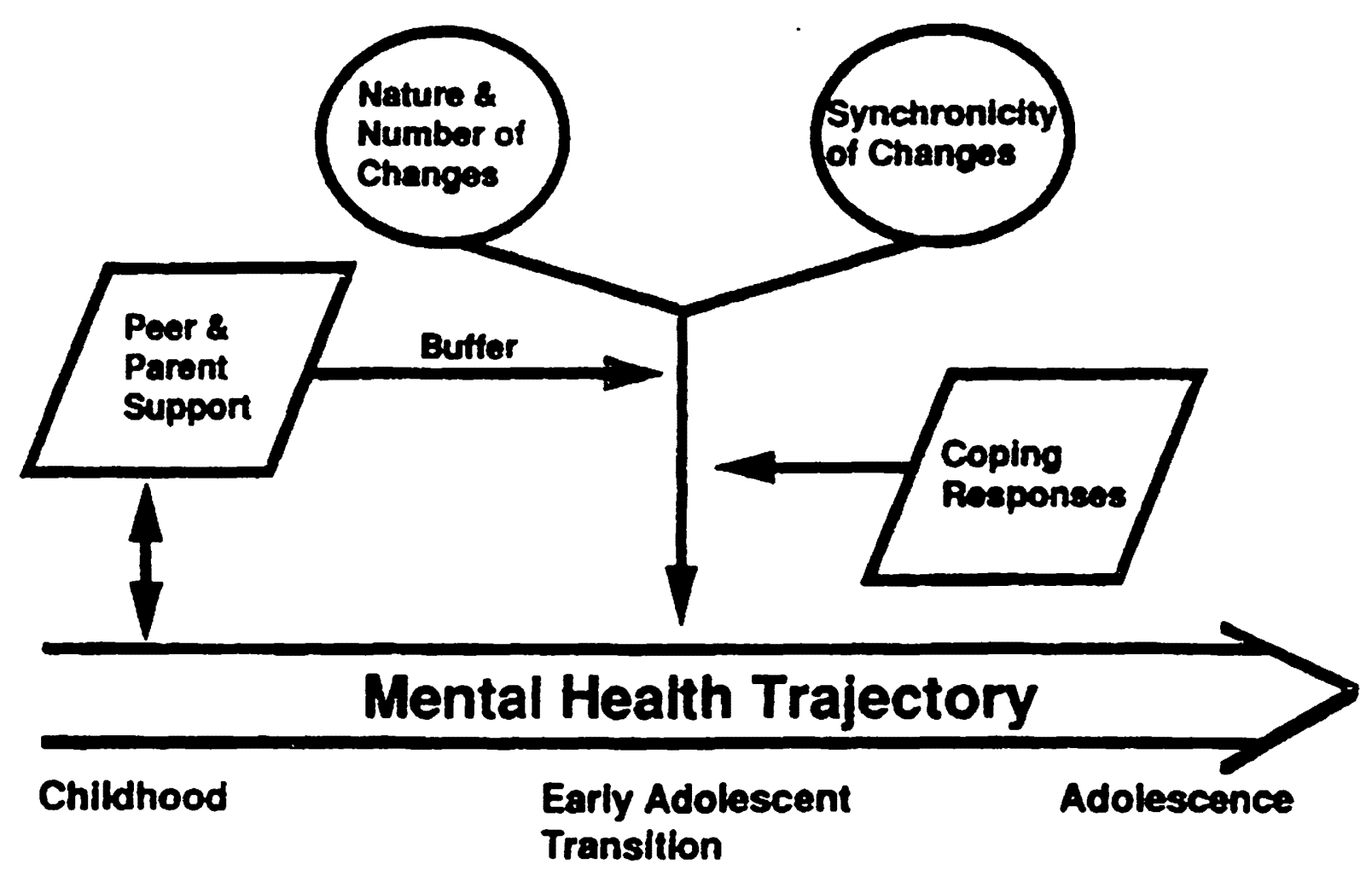

Figure 1. A model of developmental transitions.

Note. From Social intervention: Potential and constraints (p. 168). by A. C. Petersen and A. T. Ebata. 1987. New York: Walter de Gruyter. Copyright 1987 by the Walter de Gruyter Corporation. Reprinted with permission. 
Appendix $\mathrm{C}$

Time Line
Update of literature review

IRB approval

Recruitment of participants

Data collection and analysis

Completion of writing
Aug. 1999

Sept. 1999

Sept. 1999

Sept. 1999-March 2000

March 2000 


\section{Appendix D}

\section{Budget}

Instrument

Statistician

Paper, envelopes, stamps

"In kind" expenses

Processing and mailing of consent forms

Follow-up phone calls
$\$ 100$

approx. $\$ 50 / \mathrm{hr}$. x $7 \mathrm{hrs}$.

$\$ 150$

5 hours

5 hours 
Appendix $E$

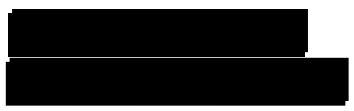

Ms. Amanda Jones

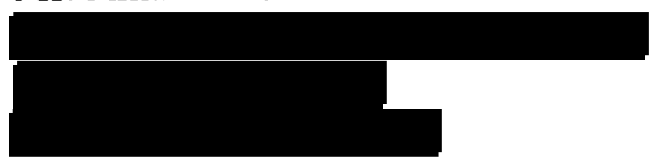

September 21, 1999

Ms. Jones:

I am writing to inquire about the possibility of utilizing Visitacion Valley Middle School (V.V.M.S.) in a research project for completion of $m$ ! Master's of Science degree in nursing and my school nurse credential. Currently 1 am working as the school nurse at V.V.M.S. four days each week.

The topic of my research is the prevention of adolescent depression. Studies have shown that teaching youth specific skills such as communication and stress management can decrease that young person's chance of becoming depressed. The "Youth Leadership" class addresses many of these skills and is currently being taught at Visitacion Valley. Middle School.

Specifically what my research would entail is administering Kovacs" Children 's Depression Inventory (CDI) to all seventh and eighth grade students who attend the "Youth Leadership" and to those seventh and eighth grade students in the third period computer class at the beginning of the school year and once again during the spring semester. The data would be analyzed to see if those seventh and eighth graders who attended the "Youth Leadership" class had lower scores on the CDI as compared with their scores prior to the intervention. Lower scores indicate the absence of depression or a mild form of depression. Subsequently. those seventh and eighth grade students who have not participated in the class will also have both sets of their scores analyzed. All scores would be kept contidential and analyzed in a group. not individually.

Attached you will find the approved Human Subjects application from San Jose State University. Also, I have enclosed a copy of the consent form I want to send to parents for your approval. Please contact me with any questions or concerns you may have. If you would like a copy of my complete research proposal let me know. Thank you for your assistance.

Sincerely.

Jacqueline Oria, BSN. RN

School District Nurse 
Appendix $F$

Human subjects application 


\section{Request to Use Human Subjects in Research Cover Sheet} Date Submitted: $\frac{\text { September 27, } 1999}{\text { Self }}$ Project Period: From Aug. 1999 To Lay 2000
Funded By:

Name: Iacqueline M. Orta

Department:

Phone Number : Work Nursing

Address: During 8am-4pm Home

Faculty Student $x$ Non-SJSU (contact)

Title of Proposed Project_Eyaluation of the effectiyeness of the "Youth_Leadershto" class in prevention of adolescent depression as measured by the ChIldren's Depression Inventory.

Abstract: Studies have shorn that teaching youth spectiftc skillis such as communtcation and stress management, can decrease that young person's chance of becoming depressed.

The "Vouch Leadership" Class that is heing taught at Vtsitacton Valley Mtddle sahool in San Erancisco addresses many of these skills. Kovacs' Chtld Denression Inyentory (CDI) will be administered to all seventh and eighth grade students in the "Youch Leadershio" and third period computer class at the beginning of the school year and again in the spring. The data will be analyzed to see if those students attendirg the "Yourh Leadership" class scored lower on che CDI.

Number of Subjects. Cla 10 Age of Sibjects: $11-14$ year 0 ds Type of Subjects: seventh and eighth grade students at V1sitacion Valley M.S. in San Fran. Proposed Research Method: non-onvivalent control group design

What Kinds of Data Will Be Collected: cesules fram Kavacs' Child Depression Invencory Is a copy or description of each data collection instrument attached: Are procedures to protect confidentiaity delineated:

YES $-\frac{x}{x}$ NO
YES $-\frac{x}{x}$ NO
YES NO
YES NO
YES $-\frac{x}{x}$ NO
Are agreements from participating institutions (on their letterhead) included: is a consent form attached: Is it on SJSU letterhead? Possible Risks: none identified

\section{Category of Risk:}

A. Research involving only minimal risk to human subjects:

Probably and magnitude of harm or discomfort are no greater than encountered in daily life.

8. Research involving reasonable risk to human subjects:

Risks to the subject are reasonable in relation to anticipated benefits to the subjects and the imporrance of the knowiedge that may reasonably be expected to result.

Please submit two copies of the completed protocol and supporting materials to: San Jose University, Human Subjects-fnstitutional Review Board, Walquist Library N., Room 125, San Jose CA 95192-0025. For questions call the HS-1RB at (408) 924-2479. 


\section{Extension of Time Request Format}

Name

Dept.

Phone: work

home

Address

Title of project

Reason for request

Changes or significant events that have occurred during the approval period

Include a copy of the original protocol.

\section{Verification of Transiation Accuracy}

Title of Proposed Project:

I, the undersigned, verify that all translated materials related to the above named study reflect the intent and spirit of English text.

\section{Responsible Faculty Member Form}

\section{Must be submitted with all student research protocols}

Title of Proposed Project: Evaluation on the Effectiveness of the "Youth Leadership" Class in the Prevention of Adolescent Depression

Student Investigator(s): Jacqueline M. Oria

Responsible Faculty Member(s): Ginny Young and Daryl Canham

$I$ (we), the undersigned, have reviewed the above named study and believe the research conforms to federal, state, and SJSU policy for the protection of human subjects in research. Further I (we) will monitor the course and conduct of the proposed research.

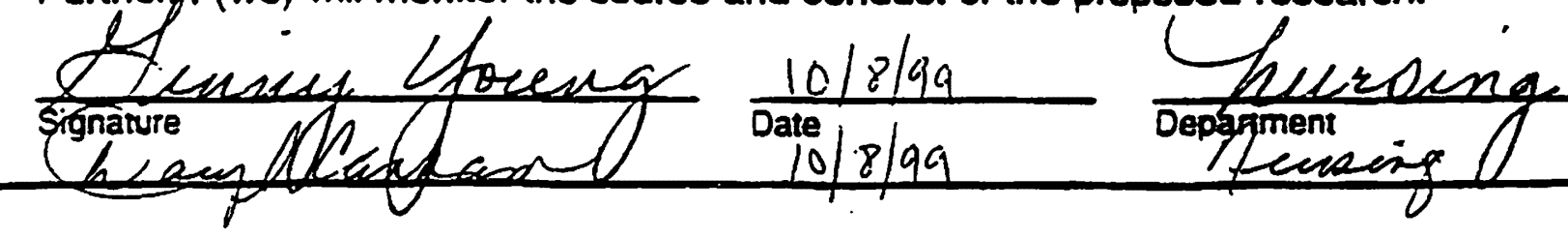


Appendix G

Agreement to Participate in Research

Responsible Investigator(s): Jackie Oria. RN

Title of Protocol: Evaluation of the Effectiveness of the "Youth Leadership" Class in the Prevention of Adolescent Depression.

1. My child or ward has been asked to participate in a research study investigating the effects prevention strategies have on decreasing the rate of depression in adolescents.

2. My child or ward will be asked to complete Kovacs ${ }^{*}$ Child Depression Inventory two times: once at the beginning of the fall semester and once during the spring semester.

3. No risks to my child or ward are anticipated.

4. As a result of this study, the "Youth Leadership" class may be offered to every student at Visitacion Valley Middle School and reviews of the skills learned may be incorporated into the health education curriculum as well.

5. The results of this study may be published. but any information that could result in my child or ward being identified will remain confidential.

6. If I have any questions about this study. I can talk with the researcher. who can be reached by telephone at (415) 656-1176. Complaints about the research may be presented to Ginny Young, (408) 924-3163. Questions or complaints about research. subjects" rights. or research-related injury may be presented to Nabil lbrahim. Ph.D. Associate Academic Vice President for Graduate Studies and Research. at (408) 924-2480.

7. I understand that choosing not to participate in this study will not affect my relations or my child or ward's relations with Visitacion Valley Middle School and/or with San Jose State University.

8. I understand that allowing my child or ward to participate is voluntary. My child or ward may refuse to participate in the study or in any part of the study. If my child or ward decides to participate in the study, he or she is free to withdraw at any time without prejudice to his/her relations with Visitacion Valley Middle School.

9. By signing this consent form. I acknowledge that I have received a signed and dated copy of the consent form.

Please initial here. 
*The signature of a parent or guardian on this document indicates approval for the child or ward to participate in the study and a statement that the child or ward is freely willing to participate.

Name of Child or Ward

$$
\text { Parent or Guardian`s Signature }
$$

$\overline{\text { Date }}$ Relations to Child or Ward

Phone

Full Mailing Address

Investigator`s Signature

Date 
Appendix $\mathrm{H}$

$(j$

$\mathcal{U}$ 
October 20, 1999

Jackueline Oria

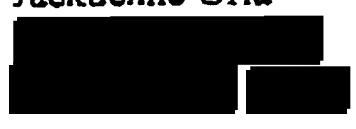

Dear Ms. Oria :

Thank you for submiting your request to conduct research on evaluating the effects of prevention strategies on decreasing the rate of depression in adolescents. We have reviewed your request and are approving it. However, our approval is at a central. District office level and is contingent upon the approvai of the school site. District approval in no way obligates any school site or teacher to participate in your study. You are still required to obtain their permission and cooperation.

Please feel free to contac: me if you have any questions. Please note that we must receive a copy of the resuits of your study when it is completed. In addition, in keeping with the District's commitment to professional deveiopment. it is critical that you share your work with the school community that assisted you in the course of your study. Good luck with your work.

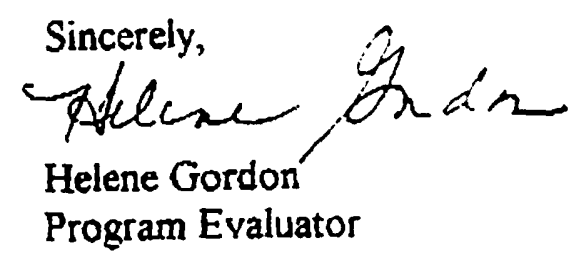




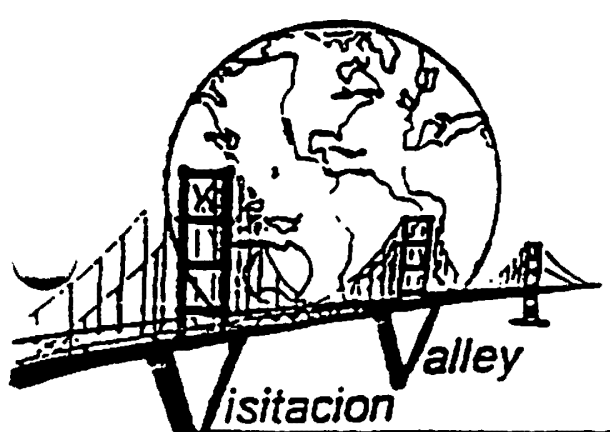

"Qualisy Educasion .. Passport so' the 21st Censury"

Visitacion VAlLey MiddLe SChocl

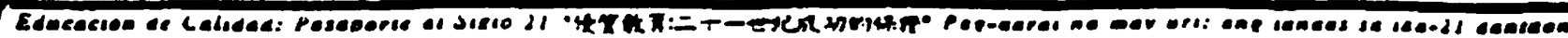

September 22, 1999

Dear Parent/Guardian:

San Francisco Unified School District will only allow your child to participate in a research study with your written consent.

Jackie Oria, RN, our school nurse, would like your child to be a part of a District approved research study. Please let me know, by checking the appropriate box on the letter attached. whether you wish the school to allow your chiid to participate.

Please sign and return the following page to your child's third period teacher as soon as possible.

Sincerely,

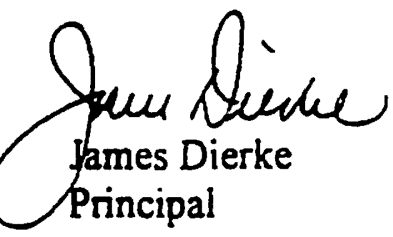




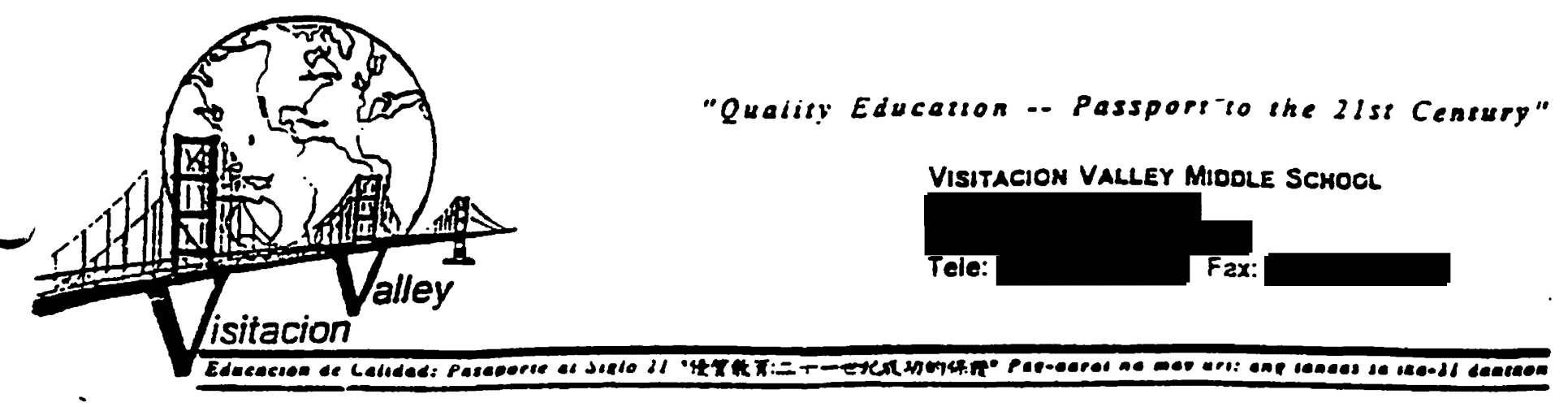

September 22, 1999

Dear Parent/Caregiver:

My name is Jackie Oria and I am the school nurse at Visitacion Valley Middle School. I am conducting a research project at the school in order to compiete a Master's degree in nursing and my School Nurse credential. I would like to include your child in my study. I would like to find out if children cope with adolescence better if they learn skills such as stress management, how to communicate effectively, anger management, and school success. These skills are taught in the Youth Court class being conducted by Erin Bristow, Visitacion Valley's Peer Resource Coordinator.

I will be utilizing a tool, Kovacs' Child Depression Inventory, to gather information about how the students are coping with adolescence. This multiple choice survey will take only 15 minutes of your child's time. Students in Ms. Bristow's "Youth Court" class and Mr. Vong's third period computer class will complete the tool once in the fall semester and once in the spring semester. I will compare the groups' scores to determine if the skills taugint in the Youth Cour class had an impact on the student's ability to cope. Individual scores will be kept confidential; only group scores will be included in my report for San Jose State University.

I would like your approval for your child to participate in this study. If you would like to review a copy of the research tool or have other questions you would like to discuss, please feel free to call me at I am avaiiable at Visitacion Valley Middle School Monday through

Thursday.

Sincerely,<smiles>N#[W]O[Mg]O[Ge]</smiles>

Jackie Oria, RN

I approve of my child being conducted by Jackie Oria, RN.

participating in the research study

I do not approve of my child

being conducted by Jackie Oria, RN. participating in the research study 
Appendix I 
Table 1

Independent Samples T-Tests for CDI Scores

Group Statisitcs

\begin{tabular}{|l|l|r|r|r|r|}
\hline \multicolumn{2}{|c|}{} & $N$ & Mean & $\begin{array}{c}\text { Std. } \\
\text { Deviation }\end{array}$ & $\begin{array}{c}\text { Std. Error } \\
\text { Mean }\end{array}$ \\
\hline $\begin{array}{l}\text { TOTAL CDI DIFFERENCE SCORE } \\
\text { (POST-CDI MINUS PRE-CDI) }\end{array}$ & CONTROL & 9 & -0.667 & 2.915 & 0.972 \\
\cline { 2 - 7 } & EXPERIMENTAL & 11 & -3.455 & 5.317 & 1.603 \\
\hline
\end{tabular}

Table 2

Independent Samples T-Tests for CDI Scores

Group Statistics

\begin{tabular}{|c|c|c|c|}
\hline & \multicolumn{3}{|c|}{ t-test for Equality of Means } \\
\hline & $t$ & $d f$ & $\begin{array}{c}\text { Sig. } \\
\text { (2-tailed) }\end{array}$ \\
\hline TOTAL CDI DIFFERENCE SCORE & 1.405 & 18 & 0.177 \\
\hline
\end{tabular}

